\title{
SOCIAL NETWORKS IN FRAME OF DIFFERENT GENERATIONS
}

\author{
Natalia Golubeva ${ }^{1,2}$, Vasilisa Orestova ${ }^{1}, \&$ Vladimir Karpuk ${ }^{1}$ \\ ${ }^{1}$ Institute of psychology, Russian State university for the humanities, 125993, Miusskaya square 6, \\ Moscow (Russia) \\ ${ }^{2}$ Psychological Institute RAE, 125009 Mochovaya 9, Moscow (Russia)
}

\begin{abstract}
Social networks now became an open space with huge opportunities for communication and obtaining the information. Although the Internet is used by people of different ages, the positioning structure of different generations in social networks is not uniform. The purpose of this work was to study social networks preferred by each group, the time spent online, the goals of Internet communication, and the degree of emotional comfort in online situation. It involved 176 respondents divided in 3 groups: I - 80 (17-19); II -60 (28-37), III-36 (38-45). The obtained data showed that social media is the leading channel for obtaining information for all groups and they often act as echo cameras. For young people most important are Instagram, Twitter, etc. For people 28-37 years Facebook remain the leader, while the third group is characterized by the absence of a preferred social network. An important advantage of "Stories" is the ability to adjust the time of the existence of information, the safety and the "transparency". The results showed a significant discrepancy in the choice of social networks between users of different generations. With age the degree of trust in information decreases, as well as the time spent online. Young people are online all day long. For them most important is constant communication and transparency. For groups II and III - is the interesting information. The situation online is ambivalent for the emotional well-being of youth, stimulating on the one hand personal development and self-improvement, and on the other, phubbing and vulnerability to shaming and cyberbullying.
\end{abstract}

Keywords: Social networks, virtual space, safety, transparency.

\section{Introduction}

The space of socialization of modern people has noticeably transformed, expanded and become more complicated. The new digital lifestyle is determined by the many real and virtual worlds. A sharp leap in the development of digital technology has increased the number of information flows (Belinskaya, Martsinkovskaya, 2018; Golubeva, 2018). Along with the expansion of the information space, the process of socialization has changed (Ayanyan, Martsinkovskaya, 2016). The high intensity of digital streams and communication in the virtual space surrounding modern youth allows us to talk about the information lifestyle of megacities (Hays et al. 2015). The direction and content of information socialization can be determined on the basis of the process of self-categorization or group identity of a modern user (Anderson et al. 2015; Gosling et al. 2011). About the priorities and interests of a person, as well as about his identity group we can judge according to the choice of the most preferred and significant source of information (Seidman, 2013).

\subsection{Problem}

It can be stated that social networks represent a platform for self-expression and self-presentation. Social networks offer endless opportunities to conduct experiments with identity. That's why it is especially important to study social networks from the point of view of features of communication and self-presentation people of different ages.

\subsection{Procedure and research methods}

There was developed a questionnaire, aimed to investigate the main social networks and the goals of different users. The study involved 176 respondents divided in 3 groups: I - 80 (17-19); II -60 (28-37), III-36 (38-45). All participants were aware of its objectives and agreed to participate in the work.

\section{Results and discussion}

Obtained results gave the opportunity to see highlight, the main functions and trends in the communication with digital space and social networks by modern users. For young users the digital space 
means primarily social networks, this is the opinion of $79 \%$ respondents. The older generation $(89 \%)$ defines digital space as a field of professional activity. All users, besides the age, consider digital space as a continuation of off-line life, with a set of new features and opportunities. Young people don't divide their world on a virtual or real one (figure 1).

Figure 1. Relation to digital space.

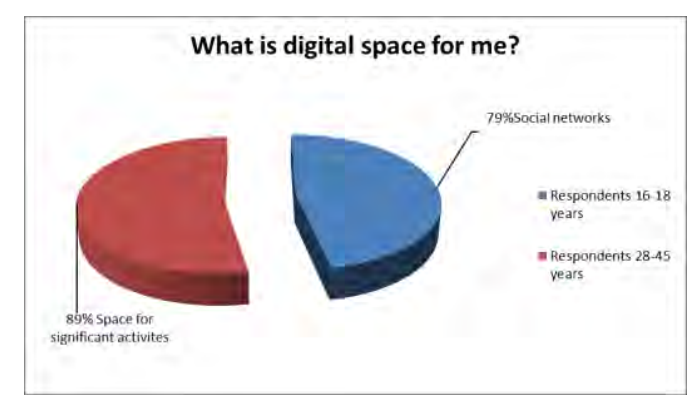

Among the key advantages of the digital space, users aged 28-37 highlight the ability to independently select information that corresponds to their interests (95\%). The key issue here is an ability to configure filters for search engines, applications and social networks so that one can select specific content, channels, subscriptions, and exclude anything else that doesn't match his or her sphere of interest.

The younger generation (17-25 years old), in contrast to the older one, highlight several important advantages of the digital space: Fast communication. Instant messaging, the ability to quickly create communication (100\%). 2. Domination of video content (91\%). 3. Freedom of self-expression. The ability to create a new version of one-self $(76 \%)$. 4. The opportunity to look at the lives and achievements of other people and get "someone else's experience" (70\%).

Young the users prefer to receive quality information and to share information. Almost all participants $(96 \%)$ noted that they try to monitor the quality of received content which should be systematized, structured and comprehensible. In other words, modern users value not only the quality of the received information, but also the way of how the information was submitted. They prefer an ability to tell simply about complex things.

The elder generations at the contrary don't simplify the information. They prefer scientific or hobby information. They also want mainly to receive, but not to share information. Only 5\% of participants have high requirements for the content they share. It is essential for them to demonstrate their professional, personal qualities and achievements to other users.

Special attention should be paid to the analysis of attitudes toward social networks. There are striking differences in the functional meaning of social networks among the participants of three age groups. For the second groups $(100 \%)$, Facebook is not only a service for establishing connections, but it is also a leading channel for getting information they are interested in. Such users do not receive totally new information on Facebook; they obtain well-known information in a more detailed form. In that way they get a confirmation of already established beliefs and attitudes. Unlike mainstream media, social networks give them what they want to hear. Users attribute similar function to Telegram channels, focusing on thematic diversity as well. As for the third group, it is characterized by the absence of a preferred social network and preferred content. Mainly they want to communicate and to receive the amazing information.

Users between 17 - 25 years old esteem Facebook in a different way. They all have their pages at this network, while $92 \%$ of respondents noted that they don't remember when they visited their page for the last time. Younger generations view social media as recreation. The main network's function is considered to be communication, mood boost and stress reliever (87\%). Every second user has indicated that comfort is essential for him or her. For this reason, there is an increased demand for the social network Vkontakte (a popular Russian social network) where users do not create their own content, but share content from other resources in order to have fun and lighten the mood. Basically, Vkontakte is a platform for downloading music, communication and watching videos (97\%).

YouTube (100\% of the entire sample) and IGTV (77\%) remain leader in video content. Services such as streaming video remain their leading positions among young people (97\%). (figure 2)

Following the motto "Live this moment", the younger generation is ready to change, to take a risk and has a desire to experiment. Such network resources make it possible to experiment with emotions and humor. These networks reflect young people's life and help them to develop their own individual style. $61 \%$ of participants declare that a Snapchat makes it possible to show their real life due to live broadcast. Facebook and Instagram present "refined" images and best moments of life. On the other hand, streaming video services show a more realistic picture of the world, where one can share his mood whether it's good or bad. So, it can be said, that if elder people like mostly "best moments" younger ones prefer "transparency". Many young people answer that they are able to stream their life 24 hours a day, 
show their entire life to other users online. Active users state that instant assessment of their actions and behavior during video streaming (likes, comments) makes them "better". They try to eat healthy food, become sportsmen, attend events, share experience, lead a proper lifestyle, etc.

Figure 2. The popularity of video streaming usage.

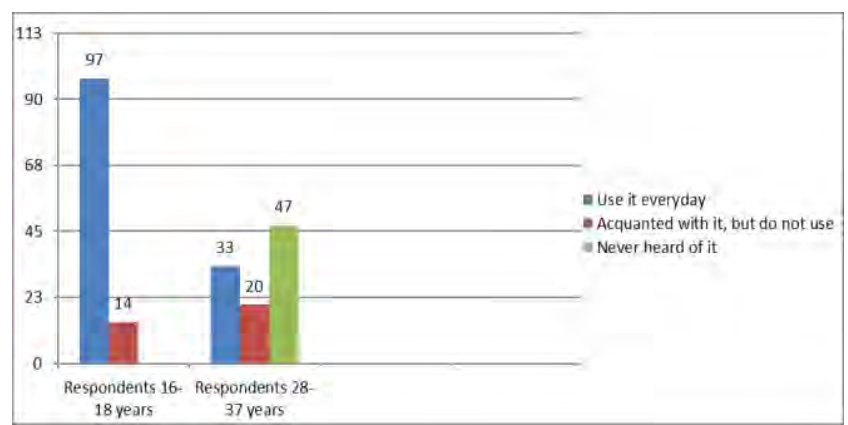

\section{Conclusion}

The obtained data makes it possible to conclude that the digital space is perceived differently by various generations. For older generations digital space is important in obtaining interesting information. Younger generation is more interested in social networks which help to communicate, improve mood and relieve stress. So, we can say that modern social networks satisfy the young people's need for information and communication. They also help them to share their emotions during communication.

For the all users digital space plays a big role in today's transitive world, especially social networks and blogging. They are important because they remove many barriers including social ones; expand the world-image and help to pick different ideas about reality. Young people consider social networks as their subjective space, that's why they are online all day long. As they say, social networks help to gain "virtual experience" and make a decision whether a person wants to get this kind of experience in real life; allow everyone to "live" many different lives.

With age the degree of trust in information decreases, as well as the time spent online. The situation online is ambivalent for the emotional well-being, stimulating on the one hand personal development and self-improvement, and on the other, phubbing and vulnerability to shaming and cyberbullying.

\section{Acknowledgment}

This work was supported by the Russian Science Foundation, project 19-18-00516 "Transitive and virtual spaces - commonality and differences".

\section{References}

Anderson C., Hildreth J.A., Howland L. (2015) Is the desire for status a fundamental human motive? A review of the empirical literature. Psychological Bulletin, 141(3), 547-601

Ayanyan A.N., Martsinkovskaya T.D. (2016), Teenager's socialization in informational space. Psychological studies, 9(46), p. 8. http://psystudy.ru

Belinsky E.P., Martsinkovskaya T.D. (2018) Identity in a transiting society: virtuality and reality. Digital society as a cultural-historical context of human development: a collection of scientific articles / Ed. R.V. Ershova. Kolomna, State Social and Humanities University. 43-48.

Golubeva, NA. (2018), Phenomenology of interpersonal and intergroup communication of modern youth in real and virtual space. RSUH/RGGU Bulletin. "Psychology. Pedagogics. Education" Series, 2(12), 45-59.

Gosling S.D., Augustine A.A., Vazire S., Holtzman N., Gaddis S. (2011) Manifestations of personality in online social networks: Self-reported Facebook-related behaviors and observable profile information. Cyberpsychology, Behavior, and Social Networking, 14(9), 483-488.

Hays N.A., Bendersky C. (2015) Not all inequality is created equal: Effects of status versus power hierarchies on competition for upward mobility. Journal of Personality and Social Psychology, $108,867-882$.

Seidman G. (2013) Self-presentation and belonging on Facebook: How personality influences social media use and motivations. Personality and Individual Differences, 54(2), 402-407. 